\title{
The effect of an autologous cellular gel-matrix integrated implant system on wound healing
}

\author{
Caroline R Weinstein-Oppenheimer*1, Alexis R Aceituno², Donald I Brown 3 , Cristian Acevedo4 ${ }^{4}$ Ricardo Ceriani5, \\ Miguel A Fuentes5, Fernando Albornoz ${ }^{4}$, Carlos F Henríquez-Roldán6,7, Patricio Morales8 , Claudio Maclean9, \\ Sergio M Tapia 5 and Manuel E Young ${ }^{4}$
}

\begin{abstract}
Background: This manuscript reports the production and preclinical studies to examine the tolerance and efficacy of an autologous cellular gel-matrix integrated implant system (IIS) aimed to treat full-thickness skin lesions.

Methods: The best concentration of fibrinogen and thrombin was experimentally determined by employing 28 formula ratios of thrombin and fibrinogen and checking clot formation and apparent stability. IIS was formed by integrating skin cells by means of the in situ gelification of fibrin into a porous crosslinked scaffold composed of chitosan, gelatin and hyaluronic acid. The in vitro cell proliferation within the IIS was examined by the MTT assay and PCNA expression. An experimental rabbit model consisting of six circular lesions was utilized to test each of the components of the IIS. Then, the IIS was utilized in an animal model to cover a 35\% body surface full thickness lesion.
\end{abstract}

Results: The preclinical assays in rabbits demonstrated that the IIS was well tolerated and also that IIS-treated rabbit with lesions of $35 \%$ of their body surface, exhibited a better survival rate $(p=0,06)$.

Conclusion: IIS should be further studied as a new wound dressing which shows promising properties, being the most remarkable its good biological tolerance and cell growth promotion properties.

\section{Background}

Natural polymers such as collagens, glycosaminoglycans, starch, chitin and chitosan have been used as biomaterials for skin substitutes because they closely resemble the native cellular milieu [1-3].

An interesting new matrix was proposed by Liu et al, 2004[4], that crosslinks chitosan, gelatin and hyaluronic acid, generating a mechanically resistant porous matrix able to support fibroblast growth. We choose this matrix as the basis to build a new system by including a fibrin gel.

Chitosan, a polysaccharide composed of glucosamine and $\mathrm{N}$-acetyl glucosamine, obtained from $\mathrm{N}$ - deacetylation of chitin, is an excellent biomaterial due to its low cost, scale availability, anti-microbial activity and biocompatibility [5]. It has been used as a cross-linked scaf-

* Correspondence: caroline.weinstein@uvach.cl

1 Departamento de Bioquímica, Facultad de Farmacia, Universidad de Valparaíso, Avenida Gran Bretaña 1093, Playa Ancha Valparaíso, Casilla 5001-V, Valparaíso, Chile

Full list of author information is available at the end of the article fold for tissue engineering with polymers such as gelatin and hyaluronic acid, resulting in a biomaterial with improved biological and mechanical properties [6]. The use of fibrin in tissue engineering practices has been increasing over the last 10 years [7-11]. Fibrin is a gel formed by polymerization after the action of the enzyme thrombin. Even though it is not a part of the normal extracellular matrix, it is temporarily present during wound healing [12]. Its use as a polymeric support for the transplant of human skin has been reported showing improved proliferation, migration and differentiation of the cells compared to keratinocytes cultured in traditional cell culture flasks $[3,8,13,14]$. It was later reported that keratinocytes cultured on fibrin maintain the cells on a proliferative state and improves the take of the grafts containing these cells [4]. Hyaluronic acid, a glicosaminoglycan component of the connective tissue, is a linear polymer of $\mathrm{d}$-glucuronic acid and $\mathrm{N}$-acetyl-D-glucosamine [12]. Although a large amount of research has been focused on the use of the cross linked type of chitosan-based scaffolds for tissue constructs, the optimiza- 
tion of cell seeding is a critical step for the successful in vitro cultivation of artificial organs.

The aim of the present research was to investigate the performance of a novel artificial skin chitosan- based scaffold containing autologous skin cells that have been included in a fibrin gel integrated inside the matrix. The ultimate goal of this research was to explore the tolerance and the efficacy of an IIS on an animal-based model.

\section{Methods \\ Biopsies}

Ortolagus cuniculus rabbits were anesthetized with ketamine/xylasine (5 $\mathrm{mg}$ and $2 \mathrm{mg} / 100 \mathrm{~g}$ of body weight) [15]. A selected dorsal area was shaved and after disinfection with a povidone-iodine complex solution, a $1-\mathrm{cm}^{2}$ biopsy was taken. All the animal experiments and procedures, including animal procurement, surgery, anesthesia, euthanasia, animal housing and surgery facilities were performed by veterinarians following the Facultad de Farmacia-Universidad de Valparaíso animal care guidelines, which are based on the Guide for the Care and Use of Laboratory Animals from the National Research Council[16].

\section{Cell isolation and culture}

The technique used for isolation and culture of skin cells was adapted from previously published reports [17-19]. Briefly, the biopsy was washed three times with $\mathrm{pH} 7.4$ $0.1 \mathrm{M}$ phosphate buffered saline (PBS) containing penicillin $(100 \mathrm{U} / \mathrm{mL}) /$ streptomycin $(100 \mu \mathrm{g} / \mathrm{mL})$. Visible fat was mechanically removed and the remnant tissue was minced with surgical blades to optimize enzymatic digestion. Afterwards, epidermis was incubated with trypsineEDTA (0.05\%-0.53 mM) and dermis with collagenase (2 $\mathrm{mg} / \mathrm{mL}$ ). Dermal and epidermal cells were washed in DMEM and then fibroblasts were cultured in DMEM/ F12 and keratinocytes in Defined Keratinocytes Medium. All the cell culture reagents were purchased from Invitrogen (Carisbad, CA, USA).

\section{Cell proliferation assay}

The MTT (Sigma-Aldrich Co, St. Louis, MO, USA) assay, which has been validated as a proliferation assay even inside microcarriers [19-23], was used to determine cell proliferation within the IIS. Rabbit keratinocytes $(13,000$ cells) and fibroblasts (7,000 cells) growing in co-culture either on conventional cell culture flasks or in an IIS were utilized at passage 2 of primary cell culture. These cells were incubated with $0.5 \% \mathrm{MTT}$ for $4 \mathrm{~h}$ at $37^{\circ} \mathrm{C}$. Next, the scaffold was disaggregated with $0.5 \%$ trypsin-5.3 $\mathrm{mM}$ EDTA for $2 \mathrm{~h}$ (Invitrogen) at $37^{\circ} \mathrm{C}$. Lysis buffer $(3 \% \mathrm{w} / \mathrm{v}$ SDS and $40 \mathrm{mM} \mathrm{HCl}$, in isopropanol) and ultrasound (15 minutes) were used to solubilize formazan. The resulting solution absorbance was read at $570 \mathrm{~nm}$.

\section{Integrated Implant System (IIS) preparation}

The procedure described by Liu et al [4], was followed to obtain a porous matrix. Briefly, a gelatin solution $(1 \% \mathrm{w} /$ $\mathrm{v})$ is mixed, with a chitosan $(2 \% \mathrm{w} / \mathrm{v})$ solution, in $1 \% \mathrm{v} / \mathrm{v}$ acetic acid and hyaluronic acid $(0,01 \% \mathrm{w} / \mathrm{v})$ solution to form a polymeric scaffold, which was then cross linked by the use of 2- morpholine-ethane sulfonic acid (MES), 1ethyl-(3,3-dimethyl-aminopropyl) carbodiimide (EDC) and N-hydroxysuccinimide (NHS). The cells were integrated onto the scaffold by in situ gelification of the fibrin $(100 \mu \mathrm{L}$ of both thrombin and fibrinogen per square centimeter).

The best concentration of fibrinogen and thrombin was experimentally determined by employing 28 formula ratios of thrombin and fibrinogen.

The optimal formula ratio $(13 \mathrm{mg} / \mathrm{mL}$ fibrinogen and $130 \mathrm{NIH} / \mathrm{mL}$ thrombin plus $30 \mathrm{mM} \mathrm{CaCl}$ ) was selected to suspend a mixture of keratinocytes and fibroblasts. Fibroblasts and keratinocytes growing on separated T25 cell culture flasks (at passage 2 of primary cell culture) were tripsinized to recover both cell populations and seeded on the matrix to reach a final concentration of $3 \times$ $10^{4} \mathrm{cell} / \mathrm{cm}^{2}[24]$.

Afterwards, the IIS is incubated overnight until implanted. In order to evaluate the contribution of the cells in the healing process, the scaffold was also used as a cell free implant system (CFIS). Both systems had an average thickness of $3 \mathrm{~mm}$ and their shape and surface were tailored to the form of the skin lesion.

\section{Comparative preclinical assay}

Six circular $2,5 \mathrm{~cm}$ diameter full-thickness excision wounds were performed at the paravertebral skin of eight young-adult rabbits. For each of the lesions, the following treatments were applied: IIS, CFIS (cell free integrated system), fibrin, autologous skin cells in fibrin, porous matrix or no treatment. The position of the treatment on the dorsal area of the rabbit was randomly assigned.

The performance of the treatments was evaluated by two blind referees, a medical doctor and a veterinarian. The outcome of each treatment was determined as graft take percentage, which is a clinical estimation of the area of the wound that is healed. Infection was categorized as a yes or no condition, and scar quality was scored based on color (1-5 scale), thickness (1-4 scale) and wound retraction (1-3 scale). The full description of the scale is summarized in Table 1.

\section{Preclinical efficacy assay}

In order to evaluate the efficacy of an IIS, a 35\% full thickness body surface lesion was performed on young adult rabbits. Twelve duplets of rabbits from the same progeny paired by body weight were either treated with an IIS or left with no treatment. The rabbits were assigned at ran- 
Table 1: Treatment outcome evaluation

\begin{tabular}{ll}
\hline Variable & Units of measure \\
\hline Graft take & Percentage \\
\hline Infection & Yes/No \\
\hline Scar color: & $1=$ hiperpigmentated \\
2 & $=$ non pigmented \\
3 & $=$ red \\
4 & $=$ almost normal \\
5 & $=$ normal \\
& \\
\hline Scar thickness & $=$ queloid \\
2 & $=$ hypertrophic \\
3 & $=$ almost normal \\
4 & $=$ normal \\
\hline Scar retraction & $1=$ very retracted \\
2 & $=$ mild retraction \\
3 & $=$ no retraction \\
\hline
\end{tabular}

The blind referees utilized the above scale to evaluate the scar quality on the six wounds model of preclinical assay. The graft take percentage is the area of the wound that healed. When examining the presence of infection a yes was quantified as a 0 , and a no was a 1. This scale gave an overall index for each wound on each rabbit.

dom to each condition. The outcome of the treatment was determined by survival, weight gain and wound closure efficiency.

\section{Histological analysis}

At the time of any wounds being clinically healed, treated or control, a biopsy of complete skin exceeding the initial size of the implant and including the region of wound healing, was taken. After fixing the biopsies in Bouin's solution for $24 \mathrm{~h}$, they were rinsed in $70 \%$ ethanol, dehydrated until 95\% ethanol, cleared in butanol, and embedded in Paraplast Plus (Sigma Chemical Co., St. Louis, MO, USA). Serial sections $5 \mu \mathrm{m}$ thick were cut in a Leica RM 2155 microtome. A selected set of sections was mounted on albumin-coated microscope slides and stained with a trichromic stain (Sigma Chemical Co, USA). The sections were stained in Harris Hematoxylin for only 75 seconds, rinsed in running tap water for 10 $\mathrm{min}$, and then rinsed in distilled water. Next, they were stained in $0.5 \%$ erythrosine B (C.I. 45430 ) - $0.5 \%$ orange G (C.I. 16230) for $30 \mathrm{~min}$, and then rinsed in distilled water. They were then immersed for $10 \mathrm{~min}$ in $0.5 \%$ phosphotungstic acid and then rinsed in distilled water. Finally, they were stained in $1 \%$ methylene blue (C.I. 42780) for 75 seconds, and quickly dehydrated in 95\% ethanol followed by $100 \%$ ethanol. After clearing in xylene, the slides were cover-slipped with Poly-Mount Xylene mounting medium (Polysciences, Inc., Warrington, U.S.A.). After- wards, photomicrographs were taken in a Leitz-Leica DMRBE microscope equipped with a Nikon Coolpix 5000 digital camera.

For the PCNA immunochemical analysis, deparaffinized and rehydrated integrated implant system (IIS) sections were incubated for $5 \mathrm{~min}$ in a microwave oven (for antigen retrieval); then cooled down to room temperature, rinsed in distilled water and incubated in $3 \% \mathrm{H}_{2} \mathrm{O}_{2}$ in absolute methanol (to block endogenous peroxidase activity). After rinsing in $50 \mathrm{mM}$ 2-amino-2-(hydroxymethyl)propane-1,3-diol (tris), pH 7.6 buffer, the slides were incubated with $2 \%$ normal horse serum in the same buffer and later incubated overnight at $4^{\circ} \mathrm{C}$ in the monoclonal antibody to Proliferating Cell Nuclear Antigen (PCNA; 1/1000) (Zymed Laboratories Inc., CA, USA); the sections were subsequently incubated with biotinylated antimouse IgG (1/500) and then processed using peroxidase-ABC (standard kit, Vector Laboratories Inc. Burlingame, CA, USA) amplification procedure and DAB (Sigma Chemical Co.) as chromogen, and finally were slightly counterstained with Harris Hematoxylin for 10 seconds.

\section{Statistical procedures Preclinical safety assay}

Two variables were compared after 10 days post implant for the IIS and CFIS: percentage of graft take and scar color using the 1-5 ranking described in the above methods. Both variables are not normally distributed, therefore a standard nonparametric method was applied as described by Hollander and Wolfe [25].

\section{Comparative preclinical assay}

Pairs of rabbits were assigned at random to treatment with an IIS or to a control group. Success, which was assessed as the rabbit surviving, was compared between both groups, applying the Mc Nemar Test $[25,26]$. The null hypothesis was that the survival of the rabbits was identical in both groups. Twelve couples of rabbits were required to work with $\alpha$ value of 0.05 and a potency of 0.9 . In addition, the variable area of cicatrisation was considered as an outcome for both the control and the case study rabbit. The area of cicatrisation was measured at the end of the analysis or at the last measurement recorded before the death of one of the pairs of rabbits. The Shapiro-Wilk test was utilized to check the normality assumption before applying the pairwise $t$ test on the mean of area of cicatrisation.

\section{Results}

\section{Fibrinogen-thrombin ratio}

Twenty-eight different formulations changing fibrinogen and thrombin concentration ratio were evaluated for clotting formation and apparent stability as shown in Figure $1 \mathrm{~A}$. Clotting was obtained by mixing equal parts of 
fibrinogen and thrombin solutions, with a concentration range of between $3-60 \mathrm{mg} / \mathrm{mL}$ and $1-300 \mathrm{NIH} / \mathrm{mL}$, respectively. The clot quality was assessed based on the capacity for clot formation, which is highly dependent on the cross linking that controls the mesh size of the network. Out of the 28 formula, 14 gave a clot, delimiting a feasible immobilization zone.

From the immobilization zone, five formulae were selected comprising a wide range of fibrinogen and thrombin concentration ratio. These five formulae were evaluated for stability, by incubating the clot in fresh cell culture media and in conditioned media, recovered from preconfluent skin cell cultures.

The optimal formula was chosen to be $13 \mathrm{mg} / \mathrm{mL}$ fibrinogen and $130 \mathrm{NIH} / \mathrm{mL}$ thrombin, which yielded fair clots that underwent fibrinolysis close after $24 \mathrm{~h}$ (Figure $1 \mathrm{~B})$, since it is desirable to obtain early fibrin degradation after implantation to allow cell delivery to the wound bed. The clotting time for this formula was approximately 1.2 sec.

\section{Cell proliferation within the IIS}

In Figure 2, a photomicrograph from the IIS after 24 hours of cell seeding is shown. Fibrin network stains with methyl blue, the scaffold appears as a red acidophilic fibrous net stained with erythrosine B (Figures 2A and 2B). It is important to highlight the close integration observed among all of the system components: matrixgel-cells. At higher magnification, the presence of cells is shown in Figure 2B. The cells with their cytoplasm and nuclei stained in purple blue with the Harris Hematoxylin, are mainly located in the fibrin colloid (indicated by arrows) and also in the interphase with the reticular matrix (indicated by arrow heads).

The cell proliferation within the IIS was examined by the MTT assay and compared with cells grown in a conventional culture flask (Figure 3). After 72 hours of cell seeding, there was a noticeable increase of cell proliferation in the IIS compared to the cells grown in a conventional culture flask. In addition, histological sections of the IIS were immunohistochemically stained for Proliferating Cell Nuclear Antigen (PCNA) (Figures 2C and 2D), a marker of cellular proliferation. The microphotographs presented show cells positively stained for this antigen, further confirming that there are cells within the IIS which are proliferating.

\section{Comparative preclinical assay}

Clinical evaluation in rabbits showed that after 10 days post implant, the graft take of CFIS was $53.75 \%$ and $81.25 \%$ for the IIS, demonstrating a significant statistical difference $(\mathrm{p}<0.10)$. Evidence of mild infection was reported in 2 out of 8 rabbits for the CFIS, and also 2 out of 8 rabbits for the IIS. Scar color after 10 days was rated as 1.9, for the CFIS and 2.75 for the IIS, demonstrating a significant statistical difference $(\mathrm{p}<0.05)$. There were no significant differences in the wound thickness or retraction of the scar during the evaluation period between the CFIS and IIS treated rabbits.

After 60 days, the wound surface was completely closed according to clinical evaluation, indicating that full epithelization occurred. A biopsy of the treated area was taken from each animal and processed as described in the above methods. Typical histological results are shown in Figure 4. Normal rabbit skin (Figure 4G) is characterized by a thin epidermis with no more than two nucleated cell layers and a dermis with connective tissue stained with methyl blue in a pale blue color and crossed with typical bundles of hair follicles (Figures $4 \mathrm{G}$ and $4 \mathrm{H}$ ). In Figures $4 \mathrm{C}, \mathrm{D}, \mathrm{E}$ and $4 \mathrm{~F}$, treated wounds are presented with a complete epithelization, showing a thick epidermis and granulation tissue in the dermis, when compared with a normal skin biopsy (Figures $4 \mathrm{G}$ and $4 \mathrm{H}$ ). In fact, in the treated wound, there is a zone of hair free epidermis, and the granulation tissue is also free of hair follicles (Figures $4 \mathrm{C}, \mathrm{D}, \mathrm{E}$ and $4 \mathrm{~F}$ ). The skin lesion treated with an IIS showed a tendency for smaller hair free areas (Figure 4E) than a CFIS treated lesion (Figure 4C) and than in untreated lesions (Figure 4A). Epidermis in the wound healed from the IIS treated lesion was thicker than the normal skin epidermis (around two nucleated cell layers, Figure $4 \mathrm{H}$ ), although thinner (around 5 nucleated cell layers; Figure 4F) than in a CFIS treated lesion, (around 10 nucleated cell layers; Figure 4D) and thinner than in the untreated lesion, (around 15 nucleated cell layers; Figure $4 \mathrm{~B})$. Overall, there was a better performance of an IIS in comparison to a CFIS.

It is important to highlight that at the time of the biopsy there were no signs of blood inflammatory cells like neutrophils, lymphocytes or macrophages, neither abscess or discharge of some kind of exudates such as serous, seropurulent, haemopurulent or pus, in any of the treated rabbits, typically associated with infection or rejection.

\section{Preclinical efficacy of the IIS}

Rabbits which survived a 35\% body surface lesion after an IIS treatment were compared with the untreated group utilizing the MacNemar test. This analysis indicated that the rabbits subjected to an IIS exhibited a better survival rate compared to the control group ( $\mathrm{p}=0.06)$.

The area of cicatrisation, of eleven pairs of rabbits was compared. One couple had to be withdrawn from this analysis because they died before five days of intervention.

The use of the Shapiro-Wilk procedure showed that the difference of area of cicatrisation is not rejected for the normality assumption required to use the paired $\mathrm{t}$ test $\mathrm{p}$ $>0.55$ ). This test indicated that the area of cicatrisation (open wound) of the IIS treated rabbits was significantly 
A

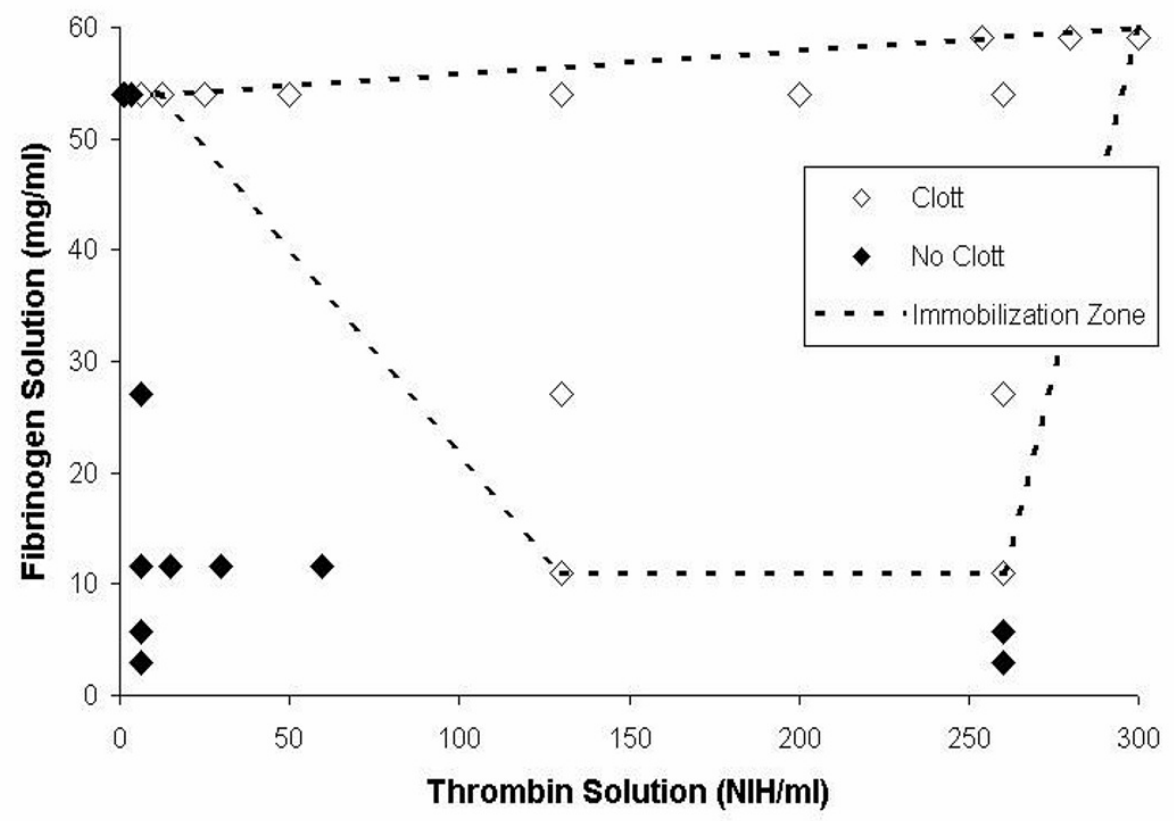

B:

$\begin{array}{lllll}\text { Clot } 1 & \text { Clot } 2 & \text { Clot } 3 & \text { Clot } 4 & \text { Clot } 5\end{array}$

\begin{tabular}{|c|c|c|c|c|c|c|}
\hline After 24 & Regular media & Stable clot & Stable clot & Stable clot & Stable clot & Stable clot \\
\hline ur & Conditioned media & Stable clot & Stable clot & Stable clot & Stable clot & Crumbled \\
\hline
\end{tabular}

clot

After $\quad$ Regular media Stable clot Crumbled Stable clot Crumbled Crumbled

72 hours

clot

clot

clot

Conditioned media

Stable clot

Crumbled

Crumbled

Crumbled

Crumbled

clot clot clot clot

Figure 1 Clotting characterization $50 \mathrm{uL}$ fibrin clots were prepared with $25 \mathrm{uL}$ of fibrinogen and $25 \mathrm{uL}$ of thrombin at various concentrations of both. A: Clotting test on 28 fibrin formulations. Positive clotting was defined as the formation of a solid and homogenous clot. The dotted line shows the immobilization zone, where proper clotting was attained. B: Clot stability test for five selected formulas from the immobilization zone. The clots were cultured in regular cell culture media or in conditioned media in 24 well plates at $37^{\circ} \mathrm{C}$. After 24 and 72 hours, clot samples were taken $(n=3)$ and visually examined to determine fibrin crumbling. 


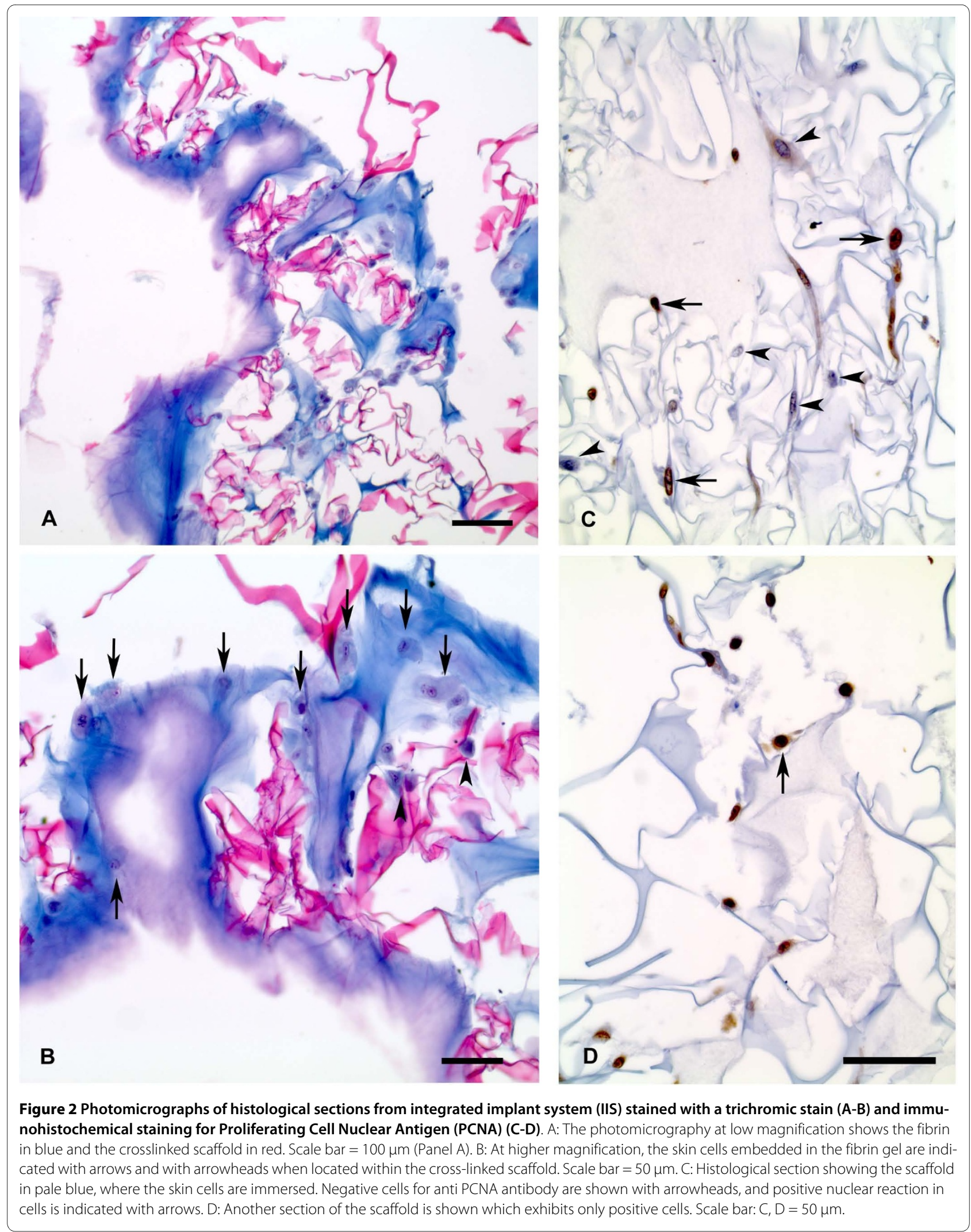




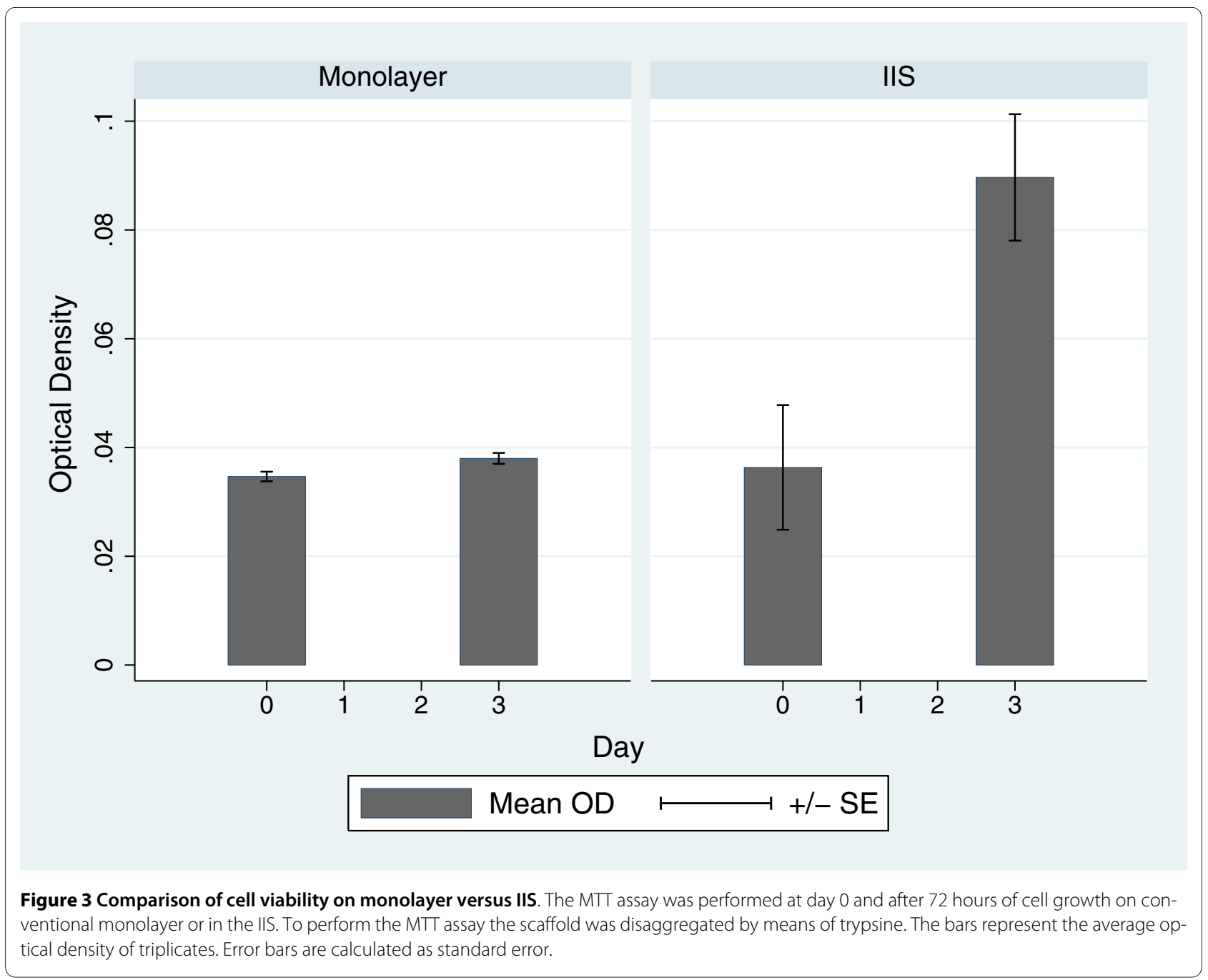

$(\mathrm{p}=0.06)$ smaller than the control rabbits. In addition, a sub analysis was performed using just the pairs of rabbits in which neither the control nor the case rabbit died. In four pairs of rabbits, the control rabbits died before the end of the study (10, 15 and 30 days). With the seven pairs of rabbits that survived at least 50 days, the difference in the area of cicatrisation among ISS treated rabbits and control rabbits exhibited a higher statistical significance $(\mathrm{p}<0.02)$.

In addition, the majority of the rabbits in the IIS treated group showed a better curve of weight gain than the non treated animals (Figure 5A). The difference in growth, in some cases, was quite remarkable (Figure 5B).

\section{Discussion}

This article describes a skin implant system built based on a novel approach that better integrates cells to a polymeric scaffold using fibrin as the cell carrier. The IIS was developed with the purpose of creating a wound dressing for regeneration of skin damaged by burns or other severe trauma. The IIS has the benefit of combining the pres- ence of cells that has been reported by some authors as helping the healing process with fibrin which is a known natural component found in injured tissue at early stages of wound repair [3,27] and a scaffold which provides mechanical handling properties in addition to biological functionalities. The scaffold is composed of chitosan, which has been reported as an antibacterial agent [28], and an inductor of the formation of granulation tissue, angiogenesis, hemostasis and the production of interleukins which induce migration and proliferation of fibroblasts and keratinocytes [28-30]. The second component is hyaluronic acid, a major component of the extracellular matrix that has chemotactic and proangiogenic properties, in addition to being a scavenger of reactive oxygen species that are overall beneficial to the wound healing process [31]. The third component is gelatin, a low cost collagen-derived protein, which has been extensively used in several polymeric devices showing cytocompatibility, low immunoreactivity, adhesiveness, flexibility, promotion of cell adhesion and cell growth $[1,2,32,33]$. 

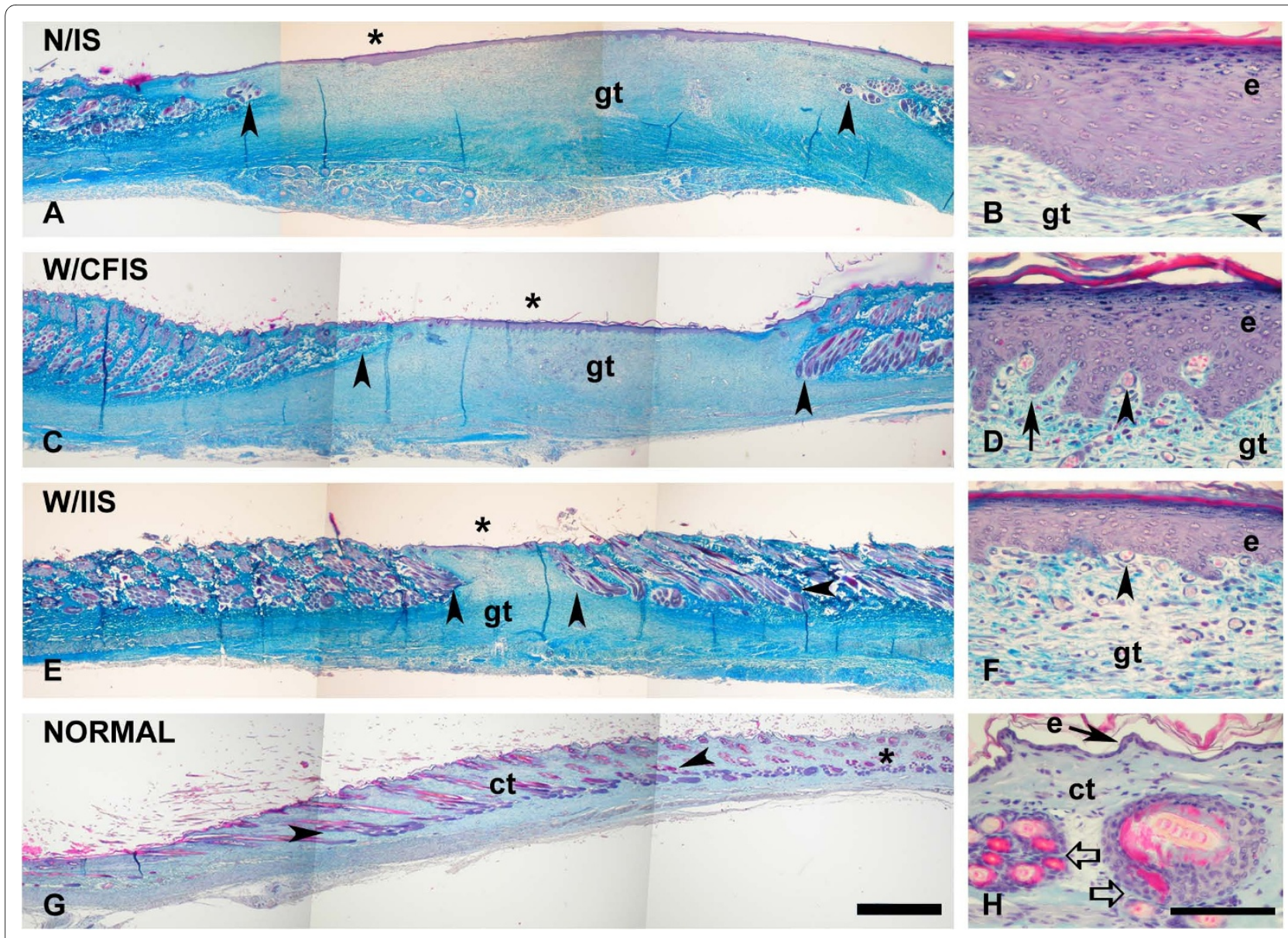

Figure 4 Photomicrographs of histological sections from skin stained with a trichromic stain. A: Wound healing in zone with no implant system (N/IS). Epidermis (asterisk) free of hairs and a region of granulation tissue below (gt), flanked by bundles of hair follicles (arrowheads). B High magnification on the asterisk region from A; thicker epidermis (e) with more than 15 nucleated cell layers and granulation tissue with blood vessels. C: Wound healing in zone treated with CFIS (W/CFIS) Epidermis (asterisk) free of hairs. Bulky granulation tissue (gt), flanked by packages of hair follicles (arrowheads). D: High magnification on the asterisk region from C; thicker epidermis (e) with more than 10 nucleated cell layers and basal finger like projections (arrow); granulation tissue with abundant blood vessels (small arrowhead). E: Wound healing in zone treated with IIS (W/IIS). Epidermis (asterisk) free of hairs and only a small region of granulation tissue below ( $\mathrm{gt}$ ), flanked by profuse bundles of hair.follicles (arrowheads). F: High magnification on the asterisk region from E; thicker epidermis (e) with more than 5 nucleated cell layers and granulation tissue with abundant blood vessels (small arrowhead). G: Normal skin (NORMAL) with very thin epidermis (asterisk) and below the connective tissue (ct) in pale blue, traversed by hair follicles (thick white arrow). H: High magnification on the asterisk region from G; epidermis (e) with no more than 2 nucleated cell layers and abundant connective tissue with bundles of hair follicles. Scale bar: A, C, E, G = $2 \mathrm{~mm} ; \mathrm{B}, \mathrm{D}, \mathrm{F}, \mathrm{H}=100 \mu \mathrm{m}$.

It is well known that the interaction between cells and the physical surface of cell culture play an important role in the outcome of the cells, influencing biological processes such as cell proliferation and differentiation. The developed system allows the cells to proliferate noticeably better than cells growing in conventional cell culture flasks. This might explain the positive clinical outcome of the IIS, since in a very short time after seeding, it improves cell proliferation within the system, a critical condition required to successfully treat severely injured skin. The observed high increase in cell proliferation may be the result of the cells actively secreting growth factors, such as PDGF [34], which may act either in a paracrine or autocrine fashion. It is known that fibrin chains (alpha and beta) and fibrinopeptides induce proliferation in skin cells by interacting with integrin receptors $[35,36]$, and a partial degradation of fibrin stimulates fibroblast proliferation in vitro [37]. The ligation of integrin receptors in skin cells induces selective mRNA expression of many cytokines and growth factors such as PDGF-BB, EGF and TGF- $\beta 1$ [38]. PDGF particularly stimulates fibroblast proliferation and the expression of integrin receptors [39]. In addition, it has been reported that cell adhesion to adequate substrates, results in a higher expression of cyclins of the G1 cell cycle phase [40]. Thus, the microenvironment within an IIS promotes cell activity which might result in the production of growth factors that are important for wound healing. 

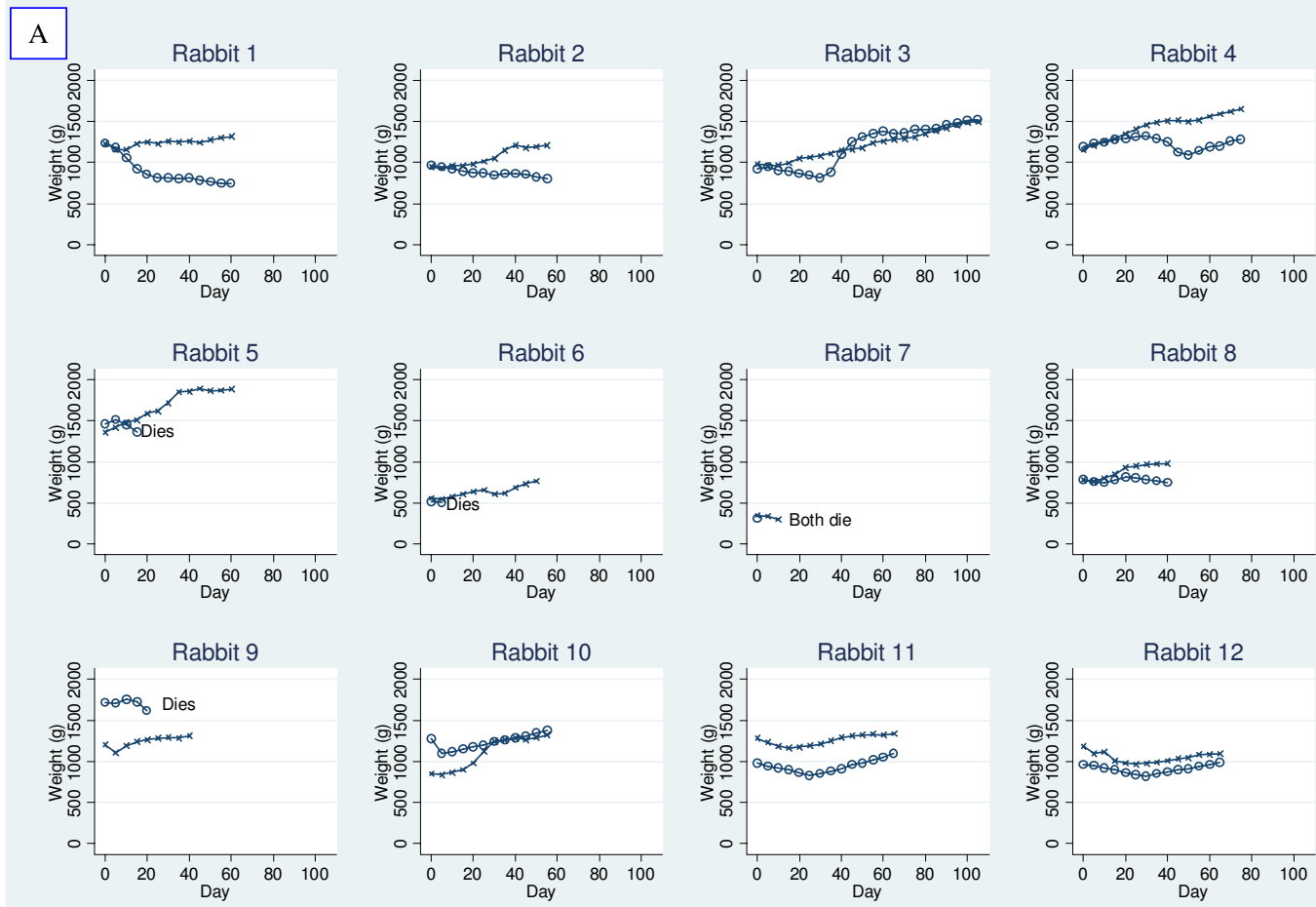

o: Control x: IIS

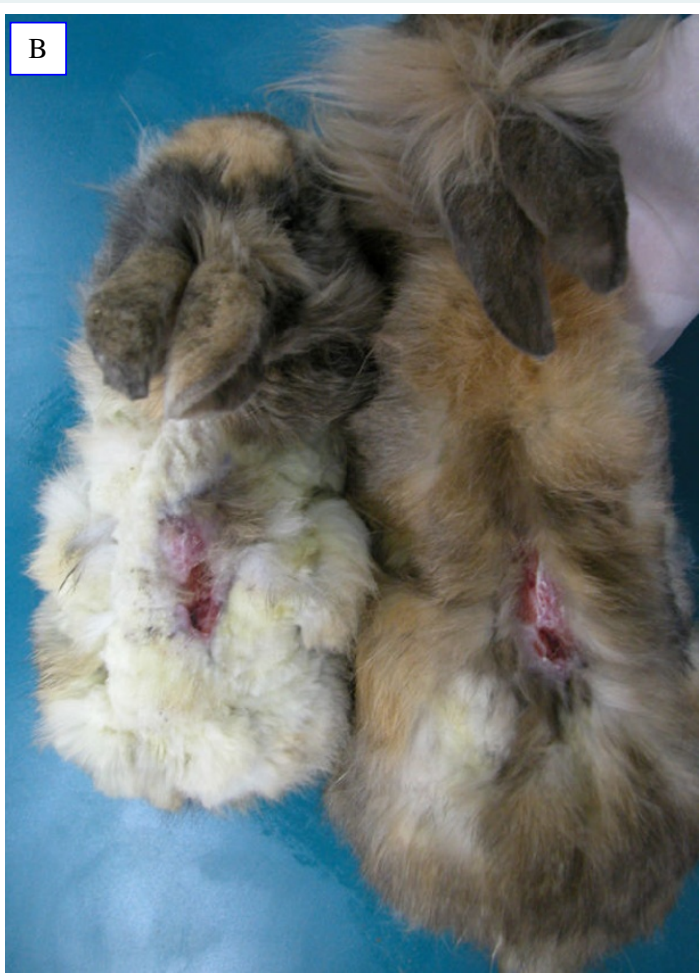

Figure 5 Effect of an IIS treatment on the weight of rabbits undergoing a life threatening condition. Panel A. Weight over time for each couple of rabbits. X: SIl treated rabbit; $0=$ untreated rabbit. Panel B. Representative picture of treated and non- treated animals after 60 days. 
In agreement with other authors, the results presented, also point towards the beneficial effects of the presence of cells in the scaffold used for dermal restoration in the wound healing process $[41,42]$. Benefits are considered in terms of a better percentage of graft take (wound healing) and histological features such as epithelization, thickness of epithelia, and the area of granulation tissue, comparing the IIS with the CFIS, both referred to normal skin (Figures $4 \mathrm{E}$ and $4 \mathrm{~F}$ with Figures $4 \mathrm{C}$ and $4 \mathrm{D}$ and Figures $4 \mathrm{G}$ and $4 \mathrm{H}$, respectively). Furthermore, CFIS applied on its own, also showed a positive effect corroborated by the histological section taken from the lesion treated with it, showing thinner epithelia and a smaller area of granulation tissue than the control lesion (Figures $4 \mathrm{C}$ and $4 \mathrm{D}$ and Figures $4 \mathrm{~A}$ and $4 \mathrm{~B}$, respectively).

The use of fibrin in dermal substitutes has shown several benefits like adjuvant of hemostasis and graft take. In addition, there is experimental evidence of fibrin acting as an antibacterial agent, a major challenge to the success of the dermal substitute. The mechanism of antibacterial action has been partially attributed to the stimulation of phagocytosis [3]. Despite the great benefits shown by several authors related to the use of fibrin as a delivery vehicle for skin cells, its weak mechanical properties have hampered its massive clinical use as a wound dressing. In this work, we present a device which allows for the use of fibrin as a cell vehicle but integrated in a scaffold, which provides mechanical strength, but also provides additional biological properties.

The preclinical experimental evidence supports that the IIS is well tolerated and efficacious because there were no signs of inflammation and all the wounds healed, showing complete epithelization. Moreover, when a life threatening lesion was performed, the IIS treated animals exhibited an overall better survival, better growth over time and smaller cicatrisation areas.

The use of autologous cells in this system is an advantage, not only because a scar of better quality is achieved, but also because it minimizes the infectious diseases transmission risk from one individual to another. However, the use of autologous cells might be seen as a drawback in view of the difficulties to store and transport of living cells and also higher costs due to their reduced possibilities of scale economy. Nonetheless, there is an autologous skin substitute currently available in the market, as well as, autologous dermal treatments for other applications. The use of animal-derived components, such as gelatine and fibrinogen, could be seen as a potential risk of transmission of certain animal borne infections, however, these and all of the components of IIS are available as pharmaceutical or tissue grade materials, presenting a risk which is comparable with products already within the pharmaceutical market.

The preclinical assays reported here show especially encouraging findings to continue with standardized clini- cal trials for the IIS and also to continue investigating the cell-biomaterial-skin interaction.

\section{Conclusions}

An IIS is a wound dressing composed of known biomaterials combined in a novel approach, allowing the integration of the cellular component within the porous matrix. This gives the cells a microenvironment which promotes in vitro cell growth and constitutes a medical device that promotes wound healing at the preclinical level.

\section{List of abbreviations}

CFIS: cell free implant system; DMEM: Dulbecco's Modified Eagle's Medium; DMEM/F12: Dulbecco's Modified Eagle's Medium/Ham's Nutrient Mixture F12; EDC: 1ethyl-(3,3-dimethyl-aminopropyl) carbodiimide; EDTA: ethylenediaminetetraacetic acid; IIS: cellular gel-matrix integrated implant system; MES: 2-morpholine-ethane sulfonic acid; MTT: 3-(4,5-Dimethylthiazol-2-yl)-2,5diphenyltetrazolium bromide; NHS: N-hydroxysuccinimide; PBS: pH 7.4 0.1 M phosphate buffered saline; SDS: sodium dodecyl sulfate.

\section{Competing interests \\ Young ME, Weinstein-Oppenheimer CR, Aceituno A, Acevedo C, Brown D and Tapia SM have a patent application for IIS.}

\section{Authors' contributions}

CWO: designed the scaffold, IIS and protocols for cell culture. She worked on the draft of the manuscript. ARA: designed and prepared the scaffold. He worked on the draft of the manuscript. DIB: performed the histological analysis and preclinical assay design and analysis. He worked on the draft of the manuscript. CA: designed cell viability assays and carried out fibrin/thrombin ratio experiments. He worked on the draft of the manuscript. RC: carried out the cell culture and cell viability assays. MAF: implemented the cell cultures and assembly of the IIS. FA: designed and prepared the IIS. CHR: performed statistical design and analysis of the preclinical assays. He worked on the draft of the manuscript. PM: was involved with the preclinical assays design, its performance and analysis. CM: participated in the design of the preclinical assay. SMT: participated in the design of the preclinical assay. MEY: developed the IIS and participated in the preclinical assay design. He worked on the draft of the manuscript.

All authors read and approved the final manuscript

\section{Acknowledgements}

This work was supported by grants from FONDEF D0211009 and FONIS SA06120092, from Conicyt and the Health Ministry of Chile.

\section{Author Details}

1Departamento de Bioquímica, Facultad de Farmacia, Universidad de Valparaíso, Avenida Gran Bretaña 1093, Playa Ancha Valparaíso, Casilla 5001-V, Valparaíso, Chile, ${ }^{2}$ Departamento de Ciencias Farmacéuticas, Facultad de Farmacia, Universidad de Valparaíso, Avenida Gran Bretaña 1093, Playa Ancha Valparaíso, Casilla 5001-V, Valparaíso, Chile, ${ }^{3}$ Departamento de Biología y Ciencias Ambientales, Facultad de Ciencias, Universidad de Valparaíso, Avenida Gran Bretaña 1111, Playa Ancha Valparaíso, Casilla 5030, Valparaíso, Chile,

${ }^{4}$ Centro de Biotecnología "Daniel Alkalay", Universidad Técnica Federico Santa María, Casilla 110-V, Valparaíso, Chile, 5 Facultad de Ciencias Naturales y Exactas, Universidad de Playa Ancha de Ciencias de la Educación Avenida Leopoldo Carvallo 270, Playa Ancha, Valparaíso, Chile, ${ }^{6}$ Centro de Estudios Estadísticos, Universidad de Valparaíso, Avenida Gran Bretaña 1041, Playa Ancha Valparaíso, Casilla 5030-V, Valparaíso, Chile, 7 Departamento de Estadística, Facultad de Ciencias, Universidad de Valparaíso, Avenida Gran Bretaña 1111, Playa Ancha, Valparaíso, Chile, ${ }^{8}$ Clínica Veterinaria La Protectora, Levarte 833, Playa Ancha, Valparaíso, Chile and ${ }^{9}$ Hospital Clínico IST, Alvarez 662, Viña del Mar, Chile 
Received: 10 January 2010 Accepted: 17 June 2010

Published: 17 June 2010

\section{References}

1. Choi YS, Hong SR, Lee YM, Song KW, Park MH, Nam YS: Studies on gelatin-containing artificial skin, II: preparation and characterization of cross-linked gelatin-hyaluronate sponge. J Biomed Mater Res 1999, 48:631-9.

2. Kim S, Nimni M, Yang Z, Han B: Chitosan/gelatin based-films cross-linked by proanthocyanidin. J Biomed Mater Res Part B 2005, 75B:442-50.

3. Currie $L$, Sharpe JR, Martin R: The use of fibrin glue in skin grafts and tissue-engineered skin replacements: A review. Plast Reconstr Surg 2001, 108:1713-26.

4. Liu H, Mao J, Yao K, Yang G, Cui L, Cao Y: A study on a chitosan-gelatinhyaluronic acid scaffold as artificial skin in vitro and its tissue engineering applications. J Biomater Sci Polymer Ed 2004, 15:25-40.

5. Mangala E, Kumar T, Baskar S, Panduranga Rao K: Development of Chitosan-Poly (vinyl alcohol) blends membranes as burn dressing. Trends Biomater Artif Organ 2003, 17:34-40.

6. Denuziere A, Ferrier D, Damour O, Domard A: Chitosan-chondroitin sulfate and chitosan-hyaluronate polyelectrolyte complexes: biological properties. Biomaterials 1998, 19:1275-85.

7. Silver FH, Wang MC, Pins GD: Preparation and use of fibrin glue in surgery. Biomaterials 1995, 16:891-903.

8. Horch RE, Bannasch H, Kopp J, Andree C, Stark GB: Single-cell suspensions of cultured human keratinocytes in fibrin-glue reconstitute epidermis. Cell Transplant 1998, 7:309-17.

9. Geer DJ, Swartz BS, Andreadis ST: Fibrin promotes migration in a threedimensional in vitro model of wound regeneration. Tissue Eng 2002, 8:787-98.

10. Christman KL, Fok HH, Sievers RE, Fang Q, Lee RJ: Fibrin glue and Skeletal Myoblasts in a Fibrin Scaffold Preserve Cardiac Function after Myocardial Infarction. Tissue Eng 2004, 10:403-9.

11. Zhang GE, Wang X, Wang Z, Zhang J, Suggs L: A PEGylated fibrin patch for mesenchymal stem cell delivery. Tissue Eng 2006, 12:9-19.

12. Mano JF, Silva GA, Azevedo HS, Malafaya PB, Sousa RA, Silva SS, Boesel LF, Oliveira JM, Santos TC, Marques AP, Neves NM, Reis RL: Natural origin biodegradable systems in tissue engineering and regenerative medicine: present status and some moving trends. JR Soc Interface 2007, 4:999-1030.

13. Jiao XY, Kopp J, Tanczos E, Voigt M, Stark GB: Culture keratinocytes suspended in fibrin glue to cover full thickness wounds on athymic nude mice: Comparison of two brands of fibrin glue. Eur J Plast Surg 1998, 21:72-6.

14. Pellegrini G, Ranno R, Stracuzzi G, Bondanza S, Guerra L, Zambruno G, Micali G, De Luca M: The control of epidermal stem cells (holoclones) in the treatment of massive full-thickness burns with autologous keratinocytes cultured on fibrin. Transplantation 1999, 68:868-79.

15. Hobbs BA, Rolhall TG, Sprenkel TL, Anthony KL: Comparison of several combinations for anesthesia in rabbits. Am J Vet Res 1991, 52:669-74.

16. National Research Council, Institute of Laboratory animal resources, commission on life sciences, Washington DC: Guide for the care and use of laboratory animals. National Academy press; 1996.

17. Rheinwald JG, Green H: Serial cultivation of strains of human epidermal keratinocytes: the formation of keratinizing colonies from single cells. Cell 1975, 6:331-43.

18. Daniels JT, Kearney JN, Ingham E: Human keratinocyte isolation and cell culture: a survey of current practices in the UK. Burns 1996, 22:35-9.

19. Hager B, Bickenbach JR, Fleckman P: Long-term culture of murine epidermal keratinocytes. J Invest Dermato/ 2004, 123:403-4.

20. Ahmed SA, Gogal RM, Walsh JE: A new rapid and simple non-radiactive assay to monitor and determine the proliferation of lymphocytes: an alternative to $(3 \mathrm{H})$ thymidine incorporation assay. J Immunol Meth 1994, 170:211-24.

21. Loveland BE, Johns TG, Mackay IR, Vaillant F, Wang ZX, Hertzog PJ: Validation of the MTT dye assay for enumeration of cells in proliferative and antiproliferative assays. Biochem Int 1992, 27:501-10.

22. Bounous DI, Campagnoli RP, Brown J: Comparison of MTT colorimetric assay and tritiated thymidine uptake for lymphocyte proliferation assays using chicken splenocytes. Avian Dis 1992, 36:1022-7.

23. Pabbruwe MB, Stewart K, Chaudhuri JB: A comparison of colorimetric and DNA quantification assays for the assessment of meniscal fibrochondrocyte proliferation in microcarrier culture. Biotechnol Lett 2005, 27:1451-5.

24. Young ME, Weinstein-Oppenheimer CR, Aceituno A, Acevedo C, Brown D, Tapia SM: Sistema de implante integrado, biocompatible,

biodegradable y bioactivo que comprende una matriz polimérica porosa estéril y un gel íntimamente relacionado a ésta, donde la gelificación ocurre en el interior de la matriz integrándose in situ a su estructura tridimensional. Uso del sistema, y su método de fabricación. Patent application CL :1397-2006.

25. Hollander M, Wolfe D: Nonparametric Statistical Methods. 2nd edition New York: John Wiley and Sons; 1999.

26. Rosner B: Fundamentals of Biostatistics. 5th edition. Pacific Grove, CA: Duxbury Thomson Learning; 2000.

27. Broughton G, Janis JE, Attinger CE: The Basic Science of Wound Healing Plast Reconstr Surg 2006:12S-34S.

28. Burkatovskaya M, Tegos GP, Swietlik E, Demidova TN, P Castano A, Hamblin MR: Use of chitosan bandage to prevent fatal infections developing from highly contaminated wounds in mice. Biomaterials 2006, 22:4157-64.

29. Wedmore I, MCManus JG, Pusateri AE, Holcomb JB: A special report on the chitosan-based hemostatic dressing: experience in current combat operations. J Trauma 2006, 60:655-8.

30. Tangsadthakun C, Kanokpanont S, Sanchavanakit N, Pichyangkura R, Banaprasert T, Tabata Y, et al:: The influence of molecular weight of chitosan on the physical and biological properties of collagen/ chitosan scaffolds. J Biomater Sci Polym Ed 2007, 18(2):147-63.

31. Manuskiatti W, Maibach HI: Hyaluronic acid and skin:wound healing and aging. Int J Dermatol 1996, 35:539-44.

32. Wang TW, Wu HC, Huang YC, Sun JS, Lin FH: Biomimetic bilayered gelatine-chondroitin-6-sulphate-hyaluronic acid biopolymer as scaffold for skin equivalent tissue engineering. Artif Organs 2006, 30(3):141-9.

33. Wang TW, Sun JS, Wu H-C, Tsuang YH, Wang WH, Lin FH: The effect of gelatine-chondroitin sulphate-hyaluronic acid skin substitute on wound healing in SCID mice. Biomaterials 2006, 27:5689-97.

34. Acevedo CA, Somoza RA, Weinstein-Oppenheimer C, Brown DI: Young ME Growth factor production from fibrin-encapsulated human keratinocytes. Biotechnol Lett 2010 in press.

35. Gray AJ, Reeves JT, Harrison NK, Winlove P, Laurent GJ: Growth factors for human fibroblasts in the solute remaining after clot formation. J Cell Sci 1990, 96:271-4

36. Gray AJ, Bishop JE, Reeves JT, Laurent GJ: A alpha and B beta chains of fibrinogen stimulate proliferation of human fibroblasts. J Cell Sci 1993, 104:409-13.

37. Gray AJ, Bishop JE, Reeves JT, Mecham RP, Laurent GJ: Partially degraded fibrinogen stimulates fibroblasts proliferation in vitro. Am J Respir Cell Mol Biol 1995, 12:684-90.

38. Shaw RJ, Doherty DE, Ritter AG, Benedict SH, Clark RA: Adherencedependent increase in human monocyte PDGF(B) mRNA is associated with increases in c-fos, c-jun, and EGF2 mRNA. J Cell Biol 1990, 111:2139-48.

39. Xu J, Clark RAF: Extracellular matrix alters PDGF regulation of fibroblast integrins. J Cell Biol 1996, 132:239-49.

40. Hulleman E, Bijvelt JJ, Verkleij AJ, Verrips CT, Boonstra J: Integrin signaling at the M/G1 transition induces expression of cyclin E. Exp Cell Res 1999, 253:422-31.

41. Horch RE, Debus M, Wagner G, Stark GB: Cultured human keratinocytes on type I collagen membranes to reconstitute the epidermis. Tissue Eng 2000, 6:53-67.

42. Cedidi CC, Wilkens L, Berger A, Ingianni G: Influence of human fibroblasts on development and quality of multilayered composite grafts in athymic nude mice. Eur J Med Res 2007, 12:541-55.

doi: 10.1186/1479-5876-8-59

Cite this article as: Weinstein-Oppenheimer et al., The effect of an autologous cellular gel-matrix integrated implant system on wound healing Journal of Translational Medicine 2010, 8:59 